University of Nebraska - Lincoln

DigitalCommons@University of Nebraska - Lincoln

USDA Forest Service / UNL Faculty Publications U.S. Department of Agriculture: Forest Service -National Agroforestry Center

July 2005

\title{
Spatial-temporal population dynamics across species range: from centre to margin
}

\author{
Qinfeng Guo \\ University of Nebraska - Lincoln \\ Mark Taper \\ Montana State Univ., Bozeman, MT \\ Michele M. Schoeneberger \\ University of Nebraska - Lincoln, mschoeneberger1@unl.edu \\ James R. Brandle \\ University of Nebraska - Lincoln, jbrandle1@unl.edu
}

Follow this and additional works at: https://digitalcommons.unl.edu/usdafsfacpub

Part of the Forest Sciences Commons

Guo, Qinfeng; Taper, Mark; Schoeneberger, Michele M.; and Brandle, James R., "Spatial-temporal population dynamics across species range: from centre to margin" (2005). USDA Forest Service / UNL Faculty Publications. 15.

https://digitalcommons.unl.edu/usdafsfacpub/15

This Article is brought to you for free and open access by the U.S. Department of Agriculture: Forest Service -National Agroforestry Center at DigitalCommons@University of Nebraska - Lincoln. It has been accepted for inclusion in USDA Forest Service / UNL Faculty Publications by an authorized administrator of DigitalCommons@University of Nebraska - Lincoln. 


\title{
Spatial-temporal population dynamics across species range: from centre to margin
}

\author{
Qinfeng Guo, Mark Taper, M. Schoenberger and J. Brandle
}

Guo, Q., Taper, M., Schoenberger, M. and Brandle, J. 2005. Spatial-temporal
population dynamics across species range: From centre to margin. - Oikos 108: 47-57.

Understanding the boundaries of species' ranges and the variations in population dynamics from the centre to margin of a species' range is critical. This study simulated spatial-temporal patterns of birth and death rates and migration across a species' range in different seasons. Our results demonstrated the importance of dispersal and migration in altering birth and death rates, balancing source and sink habitats, and governing expansion or contraction of species' ranges in changing environments. We also showed that the multiple equilibria of metapopulations across a species' range could be easily broken following climatic changes or physical disturbances either local or regional. Although we refer to our models as describing the population dynamics across whole species' range, they should also apply to small-scale habitats (metapopulations) in which species abundance follows a humped pattern or to any ecosystem or landscape where strong central-marginal (C-M) environmental gradients exist. Conservation of both central and marginal populations would therefore be equally important considerations in making management decisions.

Q. Guo, School of Natural Resources, Univ. of Nebraska, Lincoln, NE 68583-0814, USA, and U.S. Geological Survey, 8711 37th St. SE, Jamestown, ND 38401, USA (qguo@usgs.gov). - M. Taper, Dept of Ecology, Montana State Univ., Bozeman, MT 59717, USA. - M. Schoenberger, National Agroforestry Center, USDA Forest Service, Lincoln, NE 68383-0822, USA. - J. Brandle, School of Natural Resources, Univ. of Nebraska, Lincoln, NE 68583-0814, USA.

Population density tends to be highest near the centre of a species' geographical range and declines gradually toward the boundaries (Fig. 1; Whittaker 1956, Whittaker and Goodman 1979, Westman 1980, Hengeveld and Haeck 1982, Brown 1984, Maurer and Brown 1989; but see Brussard 1984). This spatial pattern, modeled well by a Gaussian distribution, may occur at any scale, ranging from a patch to the entire species' range (Brown 1984, Brown et al. 1995). Although this pattern has been intensively studied (Pielou 1969, Greig-Smith 1979), a number of questions regarding the underlying mechanisms remain unanswered (Carter and Prince 1981, 1987). Most previous theoretical and empirical studies on population dynamics focused only on the temporal patterns of local populations (May 1976), with little attention paid to the differences in birth and death rates in different habitats and migration rates across habitats within the species' range (Green 1989, Renshaw 1995, but see Hanski 1982, Pulliam 1988, Howe et al. 1991). Further, past studies either examined the dynamics of marginal populations (Holt 1983, Thomas et al. 2001) or compared the characteristics of central and marginal populations (Soulé 1973, Tabachnick and Powell 1977, Grant and Antonovics 1978, Brown 1984, Brussard 1984) with no effort made to link central and marginal populations in terms of spatial changes in birth and death rates or dispersal and migration across centralmarginal (C-M) gradients (Pulliam 1988, Case and Taper 2000). It is unclear how these spatial differences in birth and death rates within a species' range can be

Accepted 8 June 2004 
altered by dispersal or migration (Johst and Brandl 1997).

To maintain the bell-shaped distribution, a corresponding population regulation must be operating in the system (Berryman 1981), with environmental gradients from a species' range centre toward margin significantly affecting the population regulation (Linhart 1974, Grant and Antonovics 1978, Brussard 1984). In central or source habitats, the reproductive rate may exceed the mortality rate, while the opposite may occur in marginal or habitats (Pulliam 1988, Howe et al. 1991). However, empirical evidence suggests that populations with different mobility (or dispersal powers) have different mechanisms regulating population density below or approaching the carrying capacity across the species' range (Lidicker 1962, Grant 1978, Guo et al. 2000). For example, in sessile organisms with passive dispersal (e.g. plants), migration is limited and the rates of birth (b) and death (d) may be the major factors regulating population density. Under this scenario, migration is controlled by the local changes in birth and death rates. In contrast, populations of mobile organisms with active dispersal (e.g. most animals) are predominantly influenced by the dispersal and migration decisions of individuals, making the spatial distributions of these populations more sensitive to environmental changes. Hence, dispersal and migration play more critical roles in adjusting local population densities and spatial distributions (Kot et al. 1996, Primack 1996).

To better understand the patterns of species distribution, it is necessary to monitor both temporal and spatial variation of population dynamics throughout the species' range (Pease et al. 1989, Hengeveld 1990). In this study, we examined population regulations along environmental gradients through the species' range from the centre toward the margins. We asked (1) how do birth and death rates and migration change across a species' range from centre to margin and through time; (2) how do spatial environmental gradients affect population regulation and density; and (3) how do spatial and temporal population regulations along $\mathrm{C}-\mathrm{M}$ gradients affect the species' range dynamics?

\section{The spatial distribution of dynamic parameters}

In general, the most favorable conditions are found at the centre of a species' distribution, and these conditions support the highest population density (Whittaker 1956, 1967, Brussard 1984). With increasing distance away from the centre in any direction, one or more variables become less favorable, leading to a decrease in population densities. If the spatial variation in the limiting environmental factors is reasonably gradual, the spatial distribution of population density along any transect which runs through the centre of the species' ranges will tend to resemble a bell-shaped surface ( Whittaker 1967, Westman 1980, Brown 1984):

$\mathrm{N}=\mathrm{ae}^{-\mathrm{cx} \mathrm{x}^{2}}$

where $\mathrm{N}$ is population density, a is the population density at the range center and $\mathrm{c}$ is a parameter describing the rate at which density declines with distance, and $\mathrm{x}$ is the distance from the centre of the species' range (Fig. 1).

It has been argued that population density is regulated by the physiological tolerances of a species and altered by resource competition with coexisting species (Westman 1980, but see Schaffer et al. 1986). Because population density decreases from centre to margin, the regulation of population dynamics from centre to
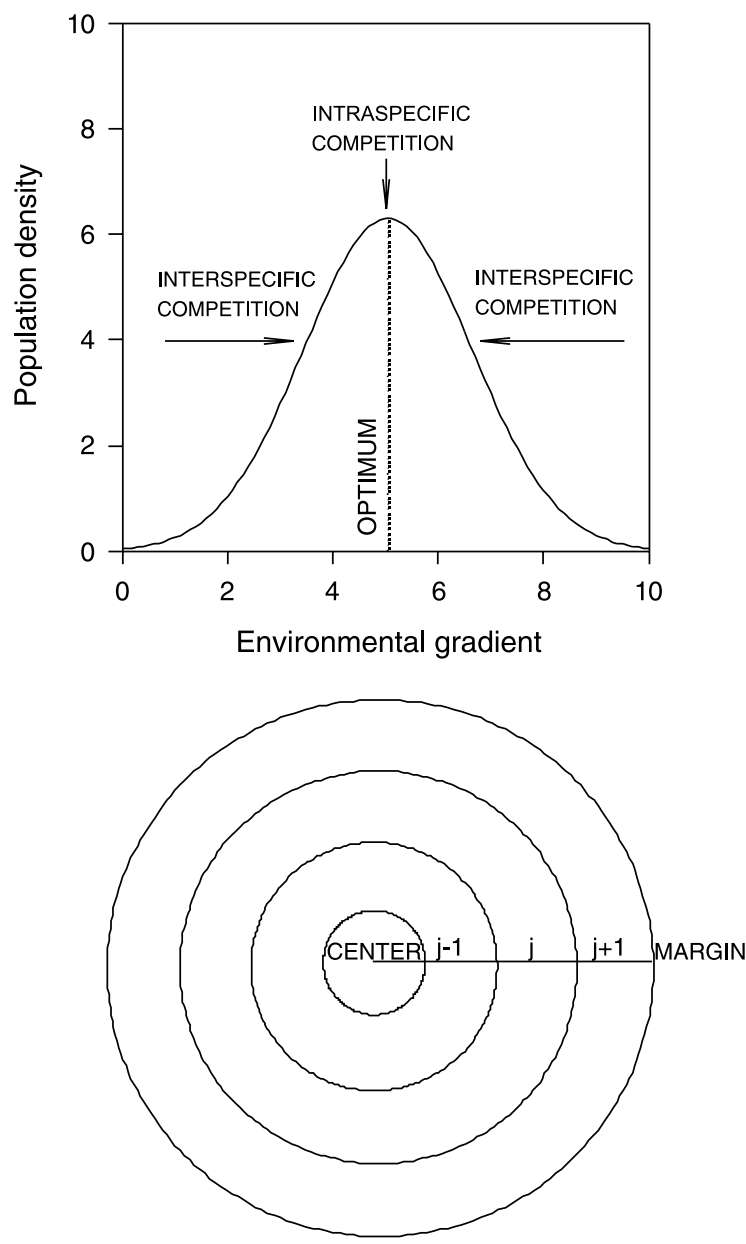

Fig. 1. Top: hypothetical Gaussian distribution and the relative levels of intra- and interspecific competition in central and marginal populations. The optimum environment, maximum habitat carrying capacity and population density are located at the centre of the species' range (the vertical dashed line). Bottom: schematic illustration of the structure of the species' range assumed in the present model, in which the species' range was divided into a number of rings from the range centre to the margin. 
margin could switch from density-dependent processes (K-selection) to densityindependent processes ( $\mathrm{r}$-selection). Therefore, a species' occupancy of its range margin would be determined by immigration, by physical stress, and by the outcome of various interspecific interactions (Dobzhansky et al. 1979, Davis et al. 1998, Stevens and Fox 1991, Case and Taper 2000). In the absence of interspecific competition, a species should reach its maximum abundance at the centre of its environmental range and be limited there by strong intraspecific competition occurs (Fig. 1). However, as a species' abundance declines toward the extremes of its tolerance at the range margin, density may be strongly affected by biotic interactions with other species (e.g. competitors, predators; Grant and Antonovics 1978). The intrinsic growth rate and the relative strength of intraspecific competition (jointly influencing the a value in Eq. 1) and the interspecific competition (influencing the $\mathrm{c}$ value) control the height and spread of the Gaussian curve (Keddy 1990; Fig. 1).

Empirical studies have shown that not only do central habitats hold higher population densities, but they also maintain greater genetic diversity (Parsons 1991). According to Barton (1985), we would also expect more gene flow into the less fit populations (asymmetric gene flow, Pulliam 1988). Thus central populations may be less sensitive to environmental fluctuations because in different years with different environments, alternative genotypes of the species would be favored (Carson 1956, Mayr 1963, Soulé 1973).

\section{The model}

We constructed a model by first dividing a species range into numerous rings (patches) surrounding the centre of the species' distribution (Fig. 1). We assumed physical conditions were homogeneous and population parameters were spatially constant within each ring. The parameters of all patches were then connected from centre to margin as a gradient to simulate the spatial variation of population parameters along the gradient. The variation in population density from the species' range centre to margin was assumed to follow a Gaussian distribution.

The population growth rate in the whole $j$ th ring, $r_{j}$, is:

$\mathrm{r}_{\mathrm{j}}=\mathrm{b}_{\mathrm{j}}-\mathrm{d}_{\mathrm{j}}+\mathrm{i}_{\mathrm{j}}-\mathrm{e}_{\mathrm{j}}$

where $b$ and $d$ are birth and death rates and $i$ and e are immigration and emigration rates, respectively. If the population is locally stable, i.e. at equilibrium, then, $r_{j}=0$. The habitat is a "source" if $\left(i_{j}-e_{j}\right)<0$. It is a "sink" if $\left(i_{j}-e_{j}\right)>0$. Similarly, for equilibrium to occur globally within the species' range, the overall population growth rate $(\mathrm{R})$ of the species is

$\mathrm{R}=\mathrm{B}-\mathrm{D}+\mathrm{I}-\mathrm{E}=0$ where B, D, I and E are total birth and death rates as well as migration in all populations of the species in question. For values of $\mathrm{R}>0$, the species' range is assumed to be expanding; if $\mathrm{R} \leq 0$, the range is stable or contracting.

The set of equilibrium points (i.e. parameters where population gain equals loss) for the population in space determine the general pattern of population abundance. However, in natural dynamic systems, the values of the four parameters are rarely balanced. The equilibrium point will therefore never truly exist under changing environments (Maurer and Brown 1989, Hanski et al. 1995). Instead, if environmental conditions are fluctuating stochastically, populations will attain what is known as a stationary distribution in both space and time (Cohen 1969, 1971). In the following sections, we will discuss the above parameters with special attention paid to the effects of dispersal and migration on population regulation and dynamics. Because dispersal and migration might have different meanings for ecologists working on various organisms, for simplicity, we adopt the broad definition of migration as "persistent and straightened-out movement" by Kennedy (1985) and its extension for plants by Dingle (1996).

A major feature in most sessile organism populations is that migration and range shifts are governed primarily by altering birth and death rates at different locations (Maurer and Brown 1989, Osawa and Allen 1993). Levin (1984) has defined immigration rate in plant populations as the ratio of the number of alien pollen and seeds to the total number of pollen and seeds in a local population. The greater the local pollen and seed production, the lower the immigration rate will be. Empirical studies suggest that a plant mainly deposits seeds and pollen locally, i.e. in neighboring habitats (Harper 1977). To model this, we assumed that emigration was deposited only into the adjacent rings and migration occurs only across neighboring rings in random directions (Fig. 1; Levin and Kerster 1974, Grant and Antonovics 1978, Okubo 1980, Levin 1988, Greene and Johnson 1989, Okubo and Levin 1989, Menges 1991, but see Skellam 1951). Thus, based on Levin's arguments and Gaussian patterns of habitat carrying capacity within a species' range, the maximum birth, death, and migration rates under optimum conditions from centre toward margin were calculated.

In contrast to sessile organisms, an important characteristic of most mobile organism populations is their active movement, which makes migration many times more efficient (Veit and Lewis 1996). Birth rate, as well as death rate, can be effectively adjusted by migration. In addition, high population density at the range centre may restrict immigration and promote emigration in order to reduce the strong intraspecific competition (Holt and Gomulkiewicz 1997, Stacey et al. 1997). Furthermore, mobile organism dispersal or migration 
may be more long range and directional compared to that of sessile populations (Primack 1996). The assumption follows that each individual can immigrate everywhere within its range until a favorable habitat is reached, making per capita birth rate intrinsic and less density-dependent (Lidicker 1962). However, as discussed later, dispersal and migration become highly critical at the species' range margin where fragmentation of habitat leads to higher extinction probabilities (Forney and Gilpin 1989).

According to Pulliam (1988), habitats near the centre serve as "sources," while those near the margin will be "sinks." The population parameters therefore should have the following variation within a species' range:

$\mathrm{b}_{\mathrm{j}-1}>\mathrm{b}_{\mathrm{j}}>\mathrm{b}_{\mathrm{j}+1}$ and $\mathrm{d}_{\mathrm{j}-1}<\mathrm{d}_{\mathrm{j}}<\mathrm{d}_{\mathrm{j}+1}$

$\mathrm{i}_{\mathrm{j}-1}<\mathrm{i}_{\mathrm{j}}<\mathrm{i}_{\mathrm{j}+1}$ and $\mathrm{e}_{\mathrm{j}-1}>\mathrm{e}_{\mathrm{j}}>\mathrm{e}_{\mathrm{j}+1}$

For the same reason, survivorship should have a distribution similar to birth rate. In other words, the death rate should be less density-dependent in populations of species with high dispersal power and this density dependence should be transferred to density dependence in immigration and emigration. Thus, in the model for passive organisms, both birth rates and survival rates are density-dependent, which we model in a Ricker like fashion (Ruxton 1995; Eq. 6), while migration is density-independent with a constant proportion $\mathrm{m}$ of births dispersing (Eq. 9). However, in our model for mobile organisms, birth and death are densityindependent (Eq. 7) while emigration and immigration are density-dependent (Eq. 10).

The population regulation processes that govern the number of individuals leaving and entering each ring can be subdivided into a density-dependent birth and death process (Shigesada and Roughgarden 1982), and a density-dependent emigration and immigration process. Because internal environmental conditions determine the intensity of competition, it also controls the migration of individuals in or out of the ring. Therefore, the movement of individuals in response to the environment is an intrinsic feature of the model.

Population regulation often refers to the ability to decrease the population size when it is above a particular level (carrying capacity), and to allow an increase in the population size if it is below that level. This particular level or carrying capacity should therefore be a point of equilibrium (Begon and Mortimer 1986). When population size reaches the habitat carrying capacity, such as under equilibrium conditions, there are four major regulation cases. First, birth and death rates rate are equal in each ring (whether they are density-dependent or not); in this case, dispersal and migration rates are density-independent and will play a minimum role in spatial-temporal variation of population dynamics. This is true for most sessile organisms. Second, birth rate follows the bell-shaped pattern (decreases from centre to margin) but death rate is density-independent. Third, birth rate is density-independent but death rate follows the bell-shaped pattern (increases from centre to margin). In these two cases, migration from central habitats to marginal habitats will occur (Fig. 2). Last, birth and death rates are not equally density-dependent, and dispersal and migration will still play a significant role in population regulation. In all cases, the birth and death rates and dispersal and migration mutually influence each other and regulate population size.

In our model, local population growth before migration within jth ring and at time $t$ is described by

$\mathrm{N}_{\mathrm{t}, \mathrm{j}}=\mathrm{N}_{\mathrm{t}, \mathrm{j}}\left(\mathrm{S}\left(\mathrm{j}, \mathrm{N}_{\mathrm{t}, \mathrm{j}}\right)+\mathrm{B}\left(\mathrm{j}, \mathrm{N}_{\mathrm{t}, \mathrm{j}}\right)\right)$

where $\mathrm{S}$ is the per capita survival rate and $\mathrm{B}$ is the per capita birth rate.

For passive dispersers, the spatially and density dependent survival and birth rate functions in each ring are:
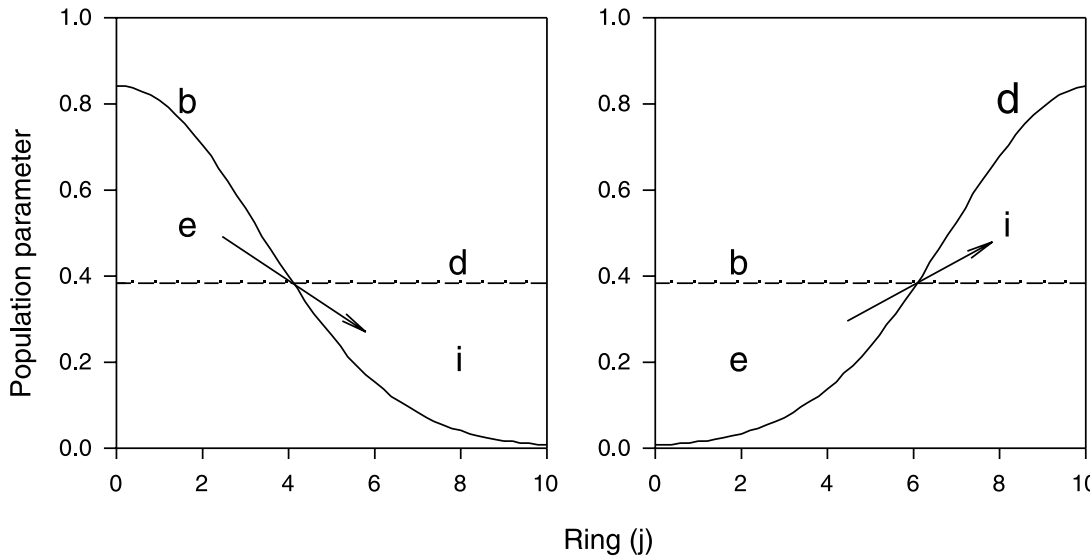

Fig. 2. Density-dependent and density-independent birth and death rates (b and $d)$. The difference between $b$ and $d$ is emigration rate $(e$; when $b-d>0)$ and immigration rate $(i ;$ when $\mathrm{b}-\mathrm{d}<0)$. 
$\mathrm{S}\left(\mathrm{j}, \mathrm{N}_{\mathrm{t}, \mathrm{j}}\right)=\mathrm{S}_{\mathrm{op}} \exp \frac{-\mathrm{j}^{2}}{2 \sigma_{\mathrm{S}}^{2}} \exp \left(\gamma \mathrm{N}_{\mathrm{t}, \mathrm{j}}\right)$,

$\mathrm{B}\left(\mathrm{j}, \mathrm{N}_{\mathrm{t}, \mathrm{j}}\right)=\mathrm{B}_{\mathrm{op}} \exp \frac{-\mathrm{j}^{2}}{2 \sigma_{\mathrm{B}}^{2}} \exp \left(\beta \mathrm{N}_{\mathrm{t}, \mathrm{j}}\right)$

where $S_{o p}$ and $B_{o p}$ are the optimal survival and birth rates, $\sigma_{\mathrm{S}}^{2}$ and $\sigma_{\mathrm{B}}^{2}$ are the spatial scale parameters for the survival and birth functions, $\gamma$ and $\beta$ are constant parameters controlling the effect of population density on survival and birth rates respectively. For active dispersers the spatially dependent and density independent dependent survival and birth rate functions in each ring are:

$\mathrm{S}\left(\mathrm{j}, \mathrm{N}_{\mathrm{t}, \mathrm{j}}\right)=\mathrm{S}_{\mathrm{op}} \exp \left(\frac{-\mathrm{j}^{2}}{2 \sigma_{\mathrm{S}}^{2}}\right)$,

$\mathrm{B}\left(\mathrm{j}, \mathrm{N}_{\mathrm{t}, \mathrm{j}}\right)=\mathrm{B}_{\mathrm{op}} \exp \left(\frac{-\mathrm{j}^{2}}{2 \sigma_{\mathrm{B}}^{2}}\right)$

Spatially explicit population dynamics given by

$N_{t+1, j}=N_{t, j}-\sum_{i \neq j} M\left(i, j, N_{t}\right)+\frac{\sum_{i \neq j} M\left(j, i, N_{t}\right) A_{i}}{A_{j}}$

where $A_{j}$ is the total area of jth ring and $M\left(i, j, N_{t}\right) A_{j}$ is the movement of individuals from the jth ring to the ith ring.

For passive migration, $\mathrm{M}\left(\mathrm{i}, \mathrm{j}, \mathrm{N}_{\mathrm{t}}\right)$ describing the shift of density from ring $\mathrm{j}$ to ring $\mathrm{i}$ is given by:

$$
\begin{aligned}
& M\left(i, j, N_{i, j}\right)=\left\{\begin{array}{l}
\frac{m B\left(j, N_{t, j}\right) N_{t, j}}{2} \text { if } i=j-1 \text { or } i=j+1 \\
m B\left(j, N_{t, j}\right) N_{t, j} \text { if } i=1 \text { and } j=0
\end{array}\right. \\
& 0 \text { otherwise, }
\end{aligned}
$$

where $\mathrm{m}$ is the proportion of births dispersing.

In contrast, the active migration function is random variable with an expected value of one and different standard deviations.

\section{Simulation results}

\section{Effects of dispersal and migration}

The effects of dispersal and migration on population regulation and source-sink habitats are illustrated in Fig. 3 (migration rates). If a species (e.g. a new emerging species or newly introduced species) is under mass expansion, its birth rate could well exceed death rate across the whole species range until such expansion stops. Conversely, if a species's range is contracting (e.g. toward extinction), the death rate will exceed the birth rate across the whole range although the difference between birth and death rates could be different in different rings across the species range (Fig. 2). Without dispersal or migration, the whole species' range only involves simple birth and death processes; and at the equilibrium point, birth rate and death rate must be balanced (i.e. $b \approx d$, or $B \approx D$ ), no matter what actual shapes the birth or death curves might be. This might be the case for populations of some sessile species. Otherwise, birth rates exceeding death rates will cause a mass emigration through dispersal from central habitats (i.e. sources) to marginal habitats (i.e. sinks). This is probably the case for most vertebrate populations (Fig. 3). In either case, the actual abundance curve of a species may indicate the migration direction of a species under environmental changes (e.g. global warming) and population usually migrates in the direction where $\mathrm{R}$ is higher on one side than the other side.

For passive populations, because of their limited dispersal power, migration only occurs across neighboring habitats and therefore the population size is mainly

$$
M\left(i, j, N_{t, j}\right)=\left\{\begin{array}{l}
0 \text { if } N_{t, j} \leq h_{j} \text { or } N_{t, j}+\frac{\sum_{k=0}^{j-1} M\left(i, k, N_{t, j}\right) A_{k}}{A_{j}} \geq h_{i} \\
\min \left(\left(\frac{\left(h_{j}-N_{t, i}\right) A_{i}-\sum_{k=0}^{j-1} M\left(i, k, N_{t, j}\right) A_{k}}{A_{j}}\right),\left(N_{t, j}-h_{j}-\frac{\sum_{k=0}^{i-1} M\left(k, j, N_{t, j}\right) A_{k}}{A_{j}}\right)\right) \text { otherwise }
\end{array}\right.
$$

where $h_{j}$ is the territory density in ring $j$.

To examine the effects of random environmental variation on population dynamics across space (rings) and time, we multiply birth rates with a log-normal controlled by birth and death rates. In active populations, however, the birth and death rates can be less density-dependent because of their greater dispersal power. However, there are exceptions in the real world. 

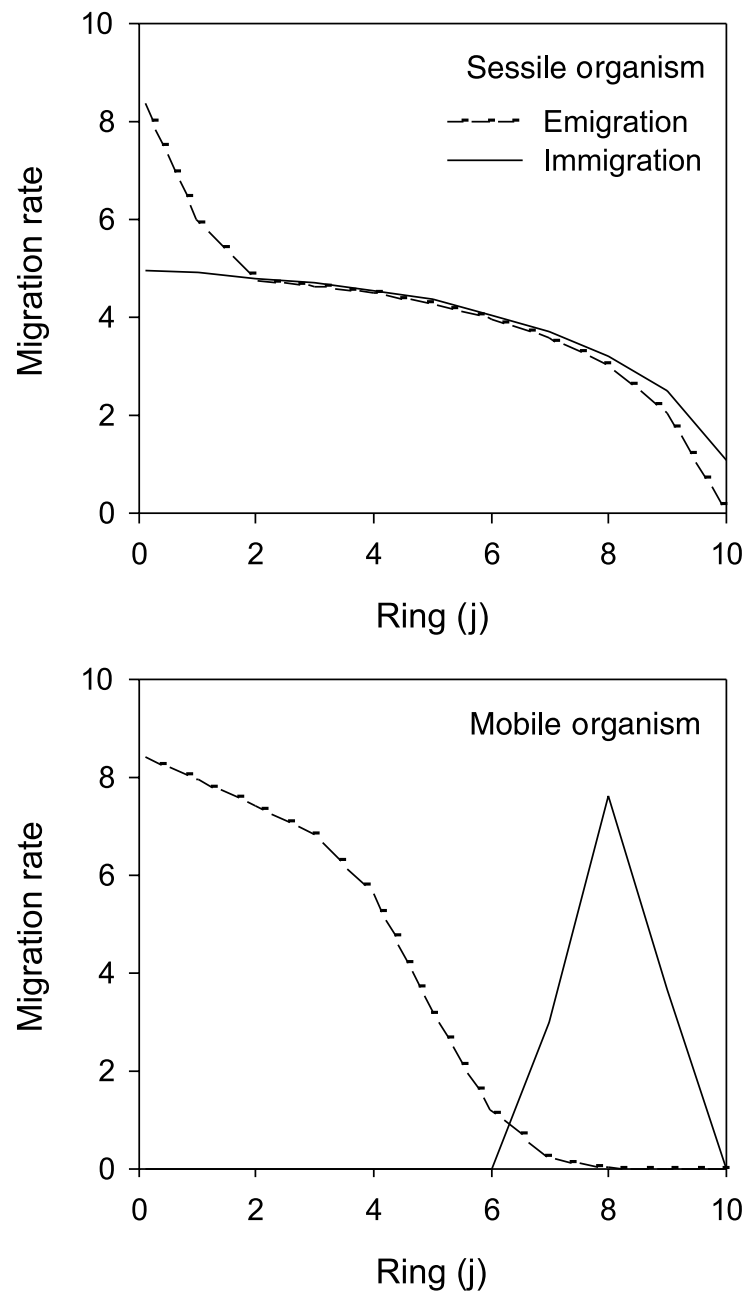

Fig. 3. A comparison of migration rates from source to sink rings between sessile (less mobile) organisms (mostly plants - top) and mobile organisms (mostly animals - bottom) $\left(\mathrm{B}_{\mathrm{op}}=0.4, \mathrm{~S}_{\mathrm{op}}=0.95, \mathrm{r}=0.0008, \mathrm{P}=0.0005, \mathrm{~h}=75\right.$, simulation time steps $=500$ ).

Some plant species have extremely high dispersal power so they may behave like most mobile species, and some animal species have passive dispersal with very low mobility so they may actually behave like most plant species in terms of dispersal or migration ability.

\section{C-M population dynamics}

Although population density across the species' range follows Gaussian distribution (Fig. 1, Eq. 1), the rings in the middle range along the $\mathrm{C}-\mathrm{M}$ gradients were found to hold the largest total population size, $\mathrm{n}_{\mathrm{j}}$ :

$\mathrm{n}_{\mathrm{j}}=\mathrm{N}_{\mathrm{j}} \pi\left(\mathrm{X}_{\mathrm{j}+1}^{2}-\mathrm{X}_{\mathrm{j}}^{2}\right)$

where $\mathrm{N}_{\mathrm{j}}$ is the population density in jth ring which follows Gaussian distribution, and $\mathrm{x}_{\mathrm{j}}$ is the distance of jth ring to the centre of the species' range.

Simulations of this model produced pictures of spatial changes in population dynamics along the $\mathrm{C}-\mathrm{M}$ gradients (Fig. 4). The species distribution boundaries fluctuate with short-term, usually cyclic environmental changes. Year-to-year precipitation or temperature variations often produce small or local habitat expansions or contractions within the species' range (Levin 1984, Maurer and Brown 1989). Mobile organism species showed higher degrees of range fluctuation under environmental variation than sessile organisms. However, long-term environmental changes will have more dramatic effects on the whole species' range, causing long-distance species migration for both passive and active species.

The habitat suitability also changed through time during population development. Suitability of internal range for further population growth decreased while suitability of peripheral rings increased. When population density was well below the carrying capacity (density-independent), central rings were most favorable. As population size increases and fluctuates around carrying capacity (density-dependent), as a result of high birth rate and low death rate, the habitat will become less favorable. By this time, the next ring becomes more favorable. Therefore, in corresponding to dramatic environmental changes, we may observe the same habitats serving as both sources and sinks in different times.

Sensitivity analysis showed that central populations are more stable, both spatially and temporally and passive populations are more sensitive to stochastic environmental changes than active populations, given the similar population sizes and time frames (Fig. 4). For both sessile and mobile organisms, marginal populations are more sensitive to environmental changes and vary among species depending on the dispersal power or migration ability of particular species, the strength of environmental variation, and the relative importance of birth and survival processes in the population dynamics. Nevertheless, the distinction between passive and active dispersers is sharp. For passive dispersers, the difference between central and marginal population variability is only modest, while for active dispersers it can be great. The populations of active dispersers in central regions are very constant and population variability rises sharply towards the margins. Where variation begins to rise depends on the magnitude of environmental variation.

\section{Discussion}

Different patches of a species' range vary in terms of resource availability or carrying capacity and therefore in their suitability for use by an organism (Kirkpatrick and 


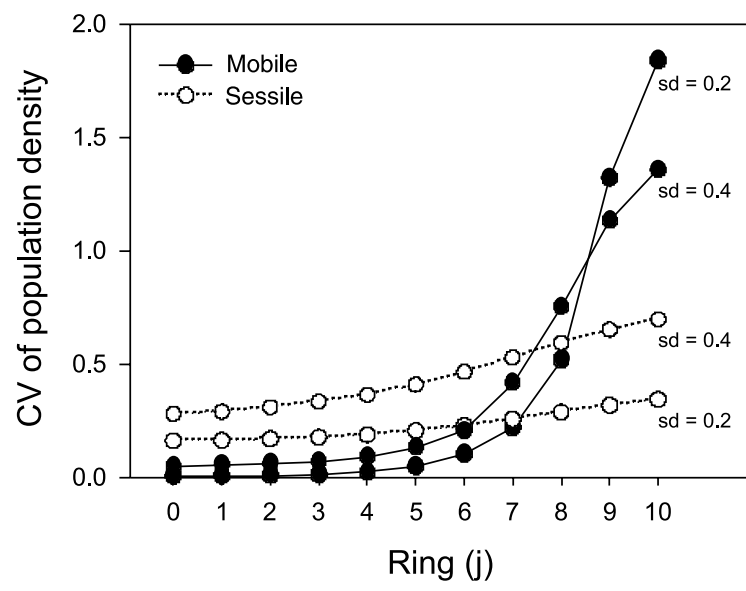

Fig. 4. Temporal variation in population density (measured by CV of population density over time) across species' range. Given the similar population sizes and time frames, sessile species showed less sensitivities to stochastic environmental variation than mobile species. Note that CVs was measured using McArdle's $\mathrm{CV}(\pi)$ which takes proportional changes into account (McArdle 1995; $\mathrm{B}_{\mathrm{op}}=0.5, \mathrm{~S}_{\mathrm{op}}=0.65$, other parameters are as in Fig. 3; sd is the standard deviation of environmental variation).

Barton 1997). It follows that environmental patches arranged from centre to margin play an important role in influencing spatial-temporal population dynamics (Shorrocks and Swingland 1990). A common feature shared by all species is that central populations, as compared to marginal populations, are less sensitive to environmental change due to their larger population size (Grant and Antonovics 1978). When environmental conditions change, the organism can avoid extinction either by adapting genetically to the new environmental condition, or by tracking its old environment across space (Pease et al. 1989, Wiens 1992). Because of their general low vagility, it is likely that sessile organisms such as plants will adapt both genetically and morphologically to environmental changes. In contrast, mobile organisms with their greater vagility are more likely to respond to environmental change by tracking their favored environment across space. The mechanisms of species response to persistent environmental change will be a critical issue in the near future as global change intensifies (Parmesan 1996).

\section{C-M gradients}

Marginal populations are believed to be more isolated and suffer higher extinction risks than central populations. However, demographic and genetic contributions from conspecific immigrants tend to reduce extinction rates of insular populations. This phenomenon is referred to as the "rescue effect" (Brown and KodricBrown 1977, Pulliam 1988, Stacey et al. 1997). Populations in marginal habitats may thus be sustained partially by a net outflow from central populations. Apparently, this process is integral to metapopulation persistence. Island biogeography theory may also apply to metapopulations, especially when the variations in patch size and isolation level from centre toward margin are considered. The marginal habitats inhabited by a species are often smaller in area, more fragmented, and, therefore, more isolated, despite the general centralmarginal migration trend. This isolation can increase in times of environmental change. Because of their supposedly unique genetic properties, marginal populations are considered very important in speciation events (Bush 1975, Brussard 1984).

In the simplest case of undirected movement, emigrants may travel equally in all directions (Fig. 1). Directed movements across one or two boundaries may occur if the local or whole range of the species is considered. In either case, the net result of the migration process will usually be a movement of organisms from the crowded rings into the less crowded ones.

The present models indicate that the birth and death per capita rates in passive populations are the most important factors. Dispersal and migration are only important locally, and the processes controlling births and deaths govern population dynamics. When the population reaches the habitat carrying capacity, high birth rate will be prohibited; or the death rate will be high, or both. Empirical data seem to support this conclusion (Grant and Antonovics 1978). On the other hand, in animal populations, the global environmental conditions within a species' range control population dynamics due to the animal's active habitat selection (Pulliam 1988).

The net migration of individuals (immigration and emigration) is the determining factor influencing species migration, range expansion/contraction, or extinction. Very high population density due to high birth rate may be reduced by emigration. Hence, emigration acts to spread the population over its range, to moderate the density of the population in any particular part of the range, and to reduce the impact of density-dependence on local birth and death rates. Once immigrants have entered a ring, they may pass through the population growth process if they are reproductively mature, but they will have different demographic characteristics compared to those they would have had in the home ring. For example, the reproductive ability may be lower and death rate may be higher.

The above difference between passive and active dispersers is due, to a large extent, to the different vagilities and propensities for directed motion of these taxa. In sessile populations such as those of plants, seeds, spores, and pollen can migrate in relatively random directions and mostly locally, whereas mobile organisms with active habitat selection can migrate long distances 
and typically toward more favorable patches (e.g. less crowded patches).

When we consider the population over its entire range, the only processes governing its numerical dynamics are the birth and death rates. However, when we focus on the species' range margin to predict the expansion or contraction or the direction of range migration, the four population parameters $(b, d, i, e)$ all play important and different roles in these processes. A passive species' range expansion, contraction, or migration is mainly induced by the differential birth (e.g. seed immigration and seedling establishment) and death rates in different parts or neighboring areas of the range, whereas a change in a mobile species' range may be controlled largely by the movements of mature individuals. The range wide responses of active and passive to environmental variation can be quite different. Passive dispersers will respond with local population fluctuations, while for active dispersers environmental variation will be expressed much more in range expansion and contraction.

Of course, what we have described as a dichotomy will actually be a continuum with range dynamics controlled largely by the mobility of the focal species. For animal species' with more passive dispersal, change in its range may be controlled by mechanisms similar to plant species' range changes.

\section{Effects of dispersal/migration}

It is critical to understand the role of dispersal and migration in population regulation along C-M environmental gradients. Passive dispersing less mobile populations (mostly plants) would show slow-paced migration following climate change. Once populations of species with poor dispersal ability reach the habitat carrying capacity, density-dependent processes would limit birth rate or increase death rate. On the other hand, in mobile populations, local birth and death rates may be less density-dependent due to the mobility of its individuals. In general, at the centre of the range higher birth rate may result in emigration to support the marginal populations where within-habitat reproduction is insufficient to balance locally higher mortality. As a consequence, populations may persist in such marginal habitats, being locally maintained by continued immigration from the species' range centre where reproduction is high and mortality is low. The distribution of mobile organisms may be more sensitive to environmental changes than those of sessile ones. Empirical data seem to support our simulation predictions (Grant and Antonovics 1978).

In many cases, distribution boundaries are not limited by physical factors such as climate; instead, they are limited by dispersal power or interactions with other species (Hutchinson 1959, Case and Taper 2000). This is demonstrated by the success of plants transplanted by humans all over the world. Interestingly, the proportion of successful animal transplantation is lower than that of plants (Williamson 1996).

Exodus from a particular environment usually occurs when resources are depleted or when the environment becomes intolerable because of physical conditions or the presence of other organisms (competitors, predators, or pathogens). In the short term, marginal plant populations can persist through vegetative growth (Olesen 1987) or autogamy (Stebbins 1950, Jain 1976). However, in the long run, marginal populations can persist only through immigration from central or "source" habitats (Brown and Kodric-Brown 1977, Pulliam 1988, Howe et al. 1991). Therefore, dispersal or migration is extremely important for those species that denude their resources or that inhabit highly variable environments. It is not surprising, therefore, that mobile organisms with highly developed dispersal powers, such as birds or insects, have been most successful in utilizing rare or temporary habitats, and many organisms have developed higher dispersal ability in marginal patches (Brussard 1984). In contrast, organisms inhabiting consistently favorable environments (i.e. central habitats) tend to be less mobile (Brussard 1984) and organisms without good dispersal powers will tend to overexploit their environments and thus be exposed to selection for mechanisms limiting their own numbers through controlling birth rate or death rate (Berryman 1981). Territorial behavior is one of the most successful tactics for achieving these ends.

Density-dependent factors may play different roles in different populations with various dispersal powers. In populations with lower dispersal or migration rates, higher intraspecific competition results in higher death rates rather than mass migration. In contrast, in most active mobile populations, higher intraspecific competition would cause higher emigration rates from crowded habitats (Stacey et al. 1997). Actively dispersing organisms have higher migration efficiency, and their birth and death rates can be effectively altered by migration. Intraor interspecific aggressiveness has an important function in stimulating migration. If, however, migration is inhibited, this same aggressiveness may cause local mortality through different ways or reduce local reproduction (birth rate). Thus, interspecific competition may be one of major forces controlling the species' range limitation (Davis et al. 1998, Case and Taper 2000).

\section{Population regulations and species' range dynamics}

The variations of population dynamics across a species' range are closely related to the dynamics of the species' 
range itself that is whether the range is expanding, contracting, or migrating. In responding to temporal environmental change, sessile and mobile populations have very different responses. In active animal populations, migration is more sensitive to environmental variation, and the density should be buffered to some extent against environmental variation except at the margins. In sessile populations, birth and death rates are more sensitive than migration. The lower the survival rates and consequently the shorter the lifespan characteristic of individuals of the species, the quicker the species range will respond. For example, annual plant density may be sensitive to seasonal, annual precipitation variation; while among tree species, the population density may exhibit sensitivity to environmental variation at larger time scales. A common feature shared by all species is that the central populations have a buffer to environmental change due to their larger population size (Carson 1956, Grant and Antonovics 1978). When environmental conditions change, the organism can avoid extinction either by adapting genetically to the new environmental conditions or by tracking its old environment across space (Pease et al. 1989). We argue that sessile organisms may tend to respond to environmental change by local adaptation while mobile organisms may tend to track their habitats through space. In fact, high mobility will tend to inhibit local adaptation (Haldane 1956, Case and Taper 2000).

\section{Implications for biological invasions and conservation}

Species range dynamics could also be implied by the changes in patches within the species' range. Our models presented here can apply also to local or metapopulation level, i.e. smaller habitat patches within the species' range. Our results show that dispersal and migration can maintain several separate populations in apparent demographic equilibrium (Maurer 1994). However, such equilibrium may be fragile due to the continuously changing environments. Because of sink populations, the effective range of a species may be less than its apparent range.

In the real world, especially the one under accelerating global warming, many species are actually either expanding (e.g. invasive species) or contracting their ranges (e.g. native species in disturbed habitats, Thomas et al. 2001). Therefore, more efforts should be made to understand such processes rather than dealing with equilibrium processes. In general, central populations hold greater genetic diversity, whereas marginal populations are more sensitive to environmental changes. Because of the close linkage between populations within the species' range, conservation and management of both central and marginal populations would be equally important (Brown 1984, Pulliam 1988, Furlow and Armijo-Prewitt 1995, Lesica and Allendorf 1995, Lomolino and Channell 1997). However, for predicting species declines or invasive expansion, monitoring boundary conditions and/or marginal populations would be more effective and informative.

Acknowledgements - We thank R. Case, T. Case, M. Harrell, R. Holt, M. Lomolino and D. Wedin for helpful comments on the earlier draft of this paper. This research was supported by grants from USDA, DOE, and USGS. M. Taper was supported by NCEAS at the University of California at Santa Barbara.

\section{References}

Barton, N. H. 1985. Analysis of hybrid zones. - Annu. Rev. Ecol. Syst. 16: 113-148.

Begon, M. and Martimer, M. 1986. Population ecology: a unified study of animals and plants. - Blackwell Sciences.

Berryman, A. A. 1981. Population systems: a general introduction. - Plenum Press.

Brown, J. H. 1984. On the relationship between abundance and distribution of species. - Am. Nat. 124: 255-279.

Brown, J. H. and Kodric-Brown, A. 1977. Turnover rates in insular biogeography: effect of immigration on extinction. - Ecology 58: 445-449.

Brown, J. H., Mehlman, D. W. and Stevens, G. C. 1995. Spatial variation in abundance. - Ecology 76: 2028-2043.

Brussard, P. F. 1984. Geographic patterns and environmental gradients: the central-marginal models in Drosophila revisited. - Annu. Rev. Ecol. Syst. 15: 25-64.

Bush, G. L. 1975. Models of animal speciation. - Annu. Rev. Ecol. Syst 6: 339-364.

Carson, H. L. 1975. Marginal homozygosity for gene arrangement in Drosophila robusta. - Science 123: 630-631.

Carter, R. N. and Prince, S. D. 1981. Epidemic models used to explain biogeogragical distribution limits. - Nature 293: $644-645$

Carter, R. N. and Prince, S. D. 1987. Distribution limits from a demographic viewpoint. - Symp. Br. Ecol. Soc. 28: 165184.

Case, T. J. and Taper, M. L. 2000. Interspecific competition, environmental gradients, gene flow, and the coevolution of species' borders. - Am. Nat. 155: 583-605.

Cohen, J. 1969. Natural primate troops and a stochastic population modeling. - Am. Nat. 103: 455-477.

Cohen, J. 1971. Casual groups of monkeys and men: stochastic models of elemental social systems. - Oxford Univ. Press.

Davis, A. J., Jenkinson, L. S., Lawton, J. H. et al. 1998. Making mistakes when predicting shifts in species range in response to global warming. - Nature 391: 783-786.

Dingle, H. 1996. Migration: the biology of life on the move. - Oxford Univ. Press.

Dobzhansky, T., Powell, J. R., Taylor, C. E. et al. 1979. Ecological variables affecting the dispersal behavior of Drosophila pseudoobscura and its relatives. - Am. Nat. 114: $325-334$.

Forney, K. A. and Gilpin, M. E. 1989. Spatial structure and population extinction: a study with Drosophila flies. - Conserv. Biol. 3: 45-51.

Furlow, F. B. and Armijo-Prewitt, T. 1995. Peripheral populations and range collapse. - Conserv. Biol. 9: 1345.

Gilpin, M. E. 1979. Spiral chaos in a predator-prey model. - Am. Nat. 113: 306-308.

Grant, P. R. 1978. Dispersal in relation to carrying capacity. - Proc. Natl Acad. Sci. (USA) 75: 2854-2858.

Grant, M. C. and Antonovics, J. 1978. Biology of ecologically marginal populations of Anthoxanthum odoratum. I. phenetics and dynamics. - Evolution 32: 822-838. 
Green, D. G. 1989. Simulated effects of fire, dispersal and spatial pattern on competition within forest mosaics. - Vegetatio 82: 139-153.

Greene, D. F. and Johnson, E. A. 1989. A model of wind dispersal of winged or plumed seeds. - Ecology 70: 339347.

Greig-Smith, P. 1979. Pattern in vegetation. - J. Ecol. 67: 755779.

Guo, Q., Brown, J. H., Valone, T. J. et al. 2000. Constraints of seed size on plant distribution and abundance. - Ecology 81: $2149-2155$

Haldane, J. B. S. 1956. The relation between density regulation and natural selection. - Proc. R. Soc. Lond. B. Biol. Sci. 145: $306-308$.

Hanski, I. 1982. Dynamics of regional distribution: the core and satellite species hypothesis. - Oikos 38: 210-221.

Hanski, I., Pöyry, J., Pakkala, T. et al. 1995. Multiple equilibria in metapopulation dynamics. - Nature 377: 618-621.

Harper, J. L. 1977. Population biology of plants. - Academic Press.

Hengeveld, R. 1990. Dynamic biogeography. - Cambridge Univ. Press.

Hengeveld, R. and Haeck, J. 1982. The distribution of abundance. I. Measurements. - J. Biogeogr. 9: 303-316.

Holt, R. D. 1983. Models for peripheral populations: the role of immigration. - In: Freedman, H. I. and Strobeck, C. (eds), Population biology. Springer-Verlag, pp. 25-32.

Holt, R. D. and Gomulkiewicz, R. 1997. How does immigration influence local adaptation? A reexamination of a familiar paradigm. - Am. Nat. 149: 563-572.

Howe, R. W., Davis, G. J. and Mosca, V. 1991. The demographic significance of "sink" populations. - Biol. Conserv. 57: $239-255$.

Hutchinson, G. E. 1959. Homage to Santa Rosalia or why are there so many kinds of animals? - Am. Nat. 93: 145-159.

Jain, S. K. 1976. Patterns of survival and microevolution in plant populations. - In: Karlin, S. and Nevo, E. (eds), Population genetics and ecology. Academic Press, pp. 4989.

Johst, K. and Brandl, R. 1997. The effects of dispersal on local population dynamics. - Ecol. Model. 104: 87-101.

Keddy, P. A. 1990. Competitive hierarchies and centrifugal organization in plant communities. - In: Grace, J. and Tilman, D. (eds), Perspectives on plant competition. Academic Press, pp. 265-290.

Kennedy, J. S. 1985. Migration, behavioural and ecological. In: Rankin, M. A. (ed.), Migration: mechanisms and adaptive significance. Contrib. Marine Science 27(suppl.), pp. 5-26.

Kirkpatrick, M. and Barton, N. 1997. Evolution of a species range. - Am. Nat. 150: 1-23.

Kot, M., Lewis, M. A. and van den Driessche, P. 1996. Dispersal data and the spread of invading organisms. - Ecology 77: 2027-2042.

Lesica, P. and Allendorf, F. W. 1995. When are peripheral populations valuable for conservation. - Conserv. Biol. 9: $753-760$.

Levin, D. A. 1984. Immigration in plants: an exercise in the subjunctive. - In: Dirzo, R. and Sarukhán, J. (eds), Perspectives on plant population ecology. Sinauer Inc., pp. 242-260.

Levin, D. A. 1988. Consequences of stochastic elements in plant migration. - Am. Nat. 132: 643-651.

Levin, D. A. and Kerster, H. W. 1974. Gene flow in seed plants. - Evol. Biol. 7: 139-220.

Lidicker, W. Z. 1962. Emigration as a possible mechanism permitting the regulation of population density below carrying capacity. - Am. Nat. 96: 29-33.

Linhart, Y. B. 1974. Intra-population differentiation in annual plants I. Veronica peregrina L. raised under non-competitive conditions. - Evolution 28: 232-243.
Lomolino, M. V. and Channell, R. 1997. Range collapse, reintroductions, and biogeogaphic guidelines for conservation. - Conserv. Biol. 12: 481-484.

Maurer, B. A. 1994. Geographical population analysis: tools for the analysis of biodiversity. - Blackwell Science.

Maurer, B. A. and Brown, J. H. 1989. Distribution consequences of spatial variation in local demographic processes. - Ann. Zool. Fenn. 26: 121-131.

May, R. M. 1976. Simple mathematical models with very complicated dynamics. - Nature 261: 459-467.

Mayr, E. 1963. Animal species and evolution. - Belknap Press.

McArdle, B. H. 1995. The temporal variability of densities: back to basics. - Oikos 74: 165-171.

Menges, E. S. 1991. Seed germination percentage increases with population size in a fragmented prairie species. - Conserv. Biol. 5: $158-164$.

Okubo, A. 1980. Diffusion and ecological problems: mathematical models. - Springer-Verlag.

Okubo, A. and Levin, S. A. 1989. A theoretical framework for data analysis of wind dispersal of seeds and pollen. - Ecology 70: 329-338.

Olesen, J. M. 1987. How do plants reproduce on their range margin? - In: Thanos, C. A. (ed.), Plant-animal interactions in Mediterranean-type ecosystems. Proc. 6th Int. Conf. Medit. Climate Ecosystems. Medecos VI. Athens, Greece, pp. 217-222.

Osawa, A. and Allen, R. B. 1993. Allometric theory explains self-thinning relationships of mountain beech and red pine. - Ecology 74: 1020-1032.

Parmesan, C. 1996. Climate and species range. - Nature 382: $765-766$

Parsons, P. A. 1991. Evolutionary rates: stress and species boundaries. - Annu. Rev. Ecol. Syst. 22: 1-18.

Pease, C. M., Lande, R. and Bull, J. J. 1989. A model of population growth, dispersal and evolution in a changing environment. - Ecology 70: 1657-1664.

Pielou, E. C. 1969. An introduction to mathematical ecology. - Wiley.

Primack, R. B. 1996. Lessons from ecological theory: dispersal, establishment, and population structure. - In: Falk, D. A., Miller, C. I. and Olwell, M. (eds), Restoring diversity: strategies for reintroduction of endangered plants. Island Press, pp. 209-233.

Pulliam, H. R. 1988. Sources, sinks, and population regulation. - Am. Nat. 132: 652-661.

Renshaw, E. 1995. Modeling biological populations in space and time. - Cambridge Univ. Press.

Ruxton, G. D. 1995. The effect of emigration and immigration on the dynamics of a discrete generation population. - J. Biosci. 20: 397-407.

Schaffer, W. M., Ellner, S. and Kot, M. 1986. Effects of noise on some dynamical models in ecology. - J. Math. Biol. 24: $479-523$

Shigesada, N. and Roughgarden, J. 1982. The role of rapid dispersal in the population dynamics of competition. - Theor. Popul. Biol. 21: 353-372.

Shorrocks, B. and Swingland, J. R. (eds.) 1990. Living in a patchy environment. - Oxford Univ. Press.

Skellam, J. G. 1951. Random dispersal in theoretical populations. - Biometrika 38: 196-218.

Soulé, M. 1973. The epistasis cycle: a theory of marginal population. - Annu. Rev. Ecol. Syst. 4: 165-187.

Stacey, P. B., Johnson, V. A. and Taper, M. L. 1997. Migration within metapopulations: the impact upon local population dynamics. - In: Hanski, I. A. and Gilpin, M. E. (eds), Metapopulation biology. Academic Press, pp. 267-291.

Stebbins, G. L. 1950. Variation and evolution in plants. - Columbia Univ. Press

Stevens, G. C. and Fox, J. F. 1991. The causes of treeline. - Annu. Rev. Ecol. Syst. 22: 177-192.

Tabachnick, W. J. and Powell, J. R. 1977. Adaptive flexibility of marginal versus central populations of Drosophila willistoni. - Evolution 31: 692-694. 
Thomas, C. D., Bodsworth, E. J., Wilson, R. J. et al. 2001. Ecological and evolutionary processes at expanding range margins. - Nature 411: 577-581.

Veit, R. R. and Lewis, M. A. 1996. Dispersal, population growth, and the Allee effects - dynamics of the house finch invasion of eastern North America. - Am. Nat. 148: 255274.

Westman, W. E. 1980. Gaussian analysis: identifying environmental factors influencing bell-shaped species distributions. - Ecology 61: 733-739.

Whittaker, R. H. 1956. Vegetation of the Great Smoky Mountains. - Ecol. Monogr. 26: 1-80.
Whittaker, R. H. 1967. Gradient analysis of vegetation. - Biol. Rev. 42: 207-264.

Whittaker, R. H. and Goodman, D. 1979. Classifying species according to their demographic strategy. I. Population fluctuations and environmental heterogeneity. - Am. Nat. 113: $185-200$.

Wiens, J. A. 1992. Ecological flows across landscape boundaries: a conceptual overview. - In: Hansen, A. D. and diCastri, F. (eds), Landscape boundaries: consequences for biotic diversity and ecological flows. Springer-Verlag, pp. 217-235.

Williamson, M. 1996. Biological invasions. - Chapman and Hall. 